Check for updates

Cite this: RSC Adv., 2017, 7, 49083

\title{
Metal doped mesoporous FeOOH nanorods for high performance supercapacitors $\uparrow$
}

\author{
Rasmita Barik, Bikash Kumar Jena and Mamata Mohapatra (D)* \\ In the present study, the effect of doping of foreign atoms on the parent atoms and the application of the \\ resultant material for energy storage are successfully investigated. A facile method is reported for successful \\ incorporation of cobalt into the regular crystal lattice of iron oxide in ethylene glycol media. As iron oxides \\ are reasonable, the Co doped nano-goethite is expected to be of potential use for supercapacitor \\ application with a high specific capacitance value of $463.18 \mathrm{~F} \mathrm{~g}^{-1}$ at $0.1 \mathrm{~A} \mathrm{~g}^{-1}$ current density. It shows \\ a cycling stability of 1000 at $1 \mathrm{~A} \mathrm{~g}^{-1}$ with $96.36 \%$ of initial capacitance. The doped goethite nanorod with \\ a band gap of $2.82 \mathrm{eV}$ and high surface area $\left(159.74 \mathrm{~m}^{2} \mathrm{~g}^{-1}\right)$ was found to be a superior electrode \\ material for supercapacitors in terms of specific capacitance and cycling capability at a particular \\ percentage of doping. The high discharge capacitance and its retention are attributed to high surface \\ area and porosity of the doped iron oxide.
}

Received 16th June 2017

Accepted 30th September 2017

DOI: 10.1039/c7ra06731c

rsc.li/rsc-advances

Among all the transition metal oxides, iron oxide has been

\section{Introduction}

Depletion of fossil fuel demands the development of new sustainable energy storage devices. Moreover, developed energy storage devices such as batteries and supercapacitors are scientifically and technologically pressure to overcome major drawbacks such as low power density and cycling stability. Electrochemical capacitors, generally called as supercapacitors, have drawn remarkable attention due to their high power density, fast charging/discharging value, less resistance and extensive cycle life. ${ }^{1-4}$ According to the electrochemistry of energy storage devices, electrochemical capacitors (ECs) are of two types: electric double layer capacitors (EDLC) and pseudocapacitors. EDLC supercapacitors have the potential to store energy on the surface where they accumulate electrolyte ions from the surface of electrode through reversible adsorption of materials. Pseudo-capacitors are developed based on faradaic redox reaction between electrode and electrolyte. ${ }^{1,5,6}$ Various transitional metal oxides/hydroxides prepared using different methods show utmost pseudocapacitive behavior and provide new insights in obtaining electrochemical capacitors with high specific capacitance and environmental compatibility. ${ }^{7-12}$ Furthermore, the development of capacitive materials with enhanced electrochemical performances with high surface area, porosity and conductivity is still one of the major challenges in the field of energy storage.

Hydro and Electrometallurgy Department, CSIR-Institute of Minerals and Materials Technology, Bhubaneswar, India, Pin-751013. E-mail: mamatamohapatra@yahoo. com

$\dagger$ Electronic supplementary information (ESI) available. See DOI: $10.1039 / \mathrm{c} 7 \mathrm{ra06731 \textrm {c }}$ proven as a promising capacitive material with low toxicity, low cost and natural richness. ${ }^{4-6,13-20}$ Forgoing research was focused on iron oxide materials but they had small specific capacitances owing to their poor electrical conductivities and surface morphology. In addition to this, improved electrode materials are required to explore the fabrication of low-cost and valuable energy devices.

Keeping the above thought in mind, the introduction of secondary metal ion concept was put forward. The coexistence of secondary metal ion during the synthesis of nano iron oxide by solution routes can have additional effect on increasing its functionalities and may pave the way for the discovery of new properties stemming from an interaction between different metal ions. In addition to this, it can be exploited for fundamental studies on the modes of precipitation of iron oxides. During the past decade, a range of metal ions has been introduced during aqueous hydrolysis of iron salts to form multicomponent based iron oxide phases where metal ions enter into the structures of iron oxide through the substitution of isomorphs and modify their properties such as crystal size, morphology, stability and dissolution behaviour. ${ }^{21-25}$ Introduction of these ions during the synthesis of iron oxides could cause phase transformation of iron oxides such as ferrihydrite to goethite or lepidocrocite to magnetite through either topotactic reformation or nucleation and recrystallization. ${ }^{26}$ During the growth process, the foreign metal ions may also adsorb and deposit onto the surface of iron oxide, thus affecting its growth behaviour. This is because the strong bonding between the adsorbed foreign metal atoms and the iron oxide substrate have ability to change the mode of hydrolysis and precipitation mechanism. Therefore, the introduction of foreign metal ions 
represents a very attractive strategy for selective precipitation of phase with tailored shapes. Incorporated foreign metal ions or dopants in sol-gel chemistry also offer a convenient method for producing functional materials. Morphology and chemical doping also affect the electrochemical performance of metal oxides when applied individually.

Different forms of iron oxides precipitated through coordinating solvent assisted methods may prove to be better candidates for electrode materials in supercapacitors. To achieve enhancement in their conductivity, some modifications can be performed to alter the physical properties of iron oxides. It has been reported that other metal ions can dramatically enhance the magnetic and electrical properties of different iron oxides by changing the nature and concentration of defects. ${ }^{27,28}$

In this study, the effect of addition of cobalt as secondary ions during precipitation of iron oxide through solvent mediation is investigated. The effects of these ions on the electrochemical properties of synthesized iron oxide materials are also included herein. Furthermore, the structural, optical, and morphological properties of synthesized Co doped nanomaterials were characterized by XRD, UV, FESEM, TEM, EDAX and their surface area and pore size distributions were analysed.

\section{Experimental}

$\mathrm{Fe}\left(\mathrm{NO}_{3}\right)_{3} \cdot 9 \mathrm{H}_{2} \mathrm{O}$ (E-Merck, India), ethylene glycol ( $\mathrm{HO} \cdot \mathrm{CH}_{2}$. $\left.\mathrm{CH}_{2} \cdot \mathrm{OH}\right)$ and cobalt sulfate $\left(\mathrm{CuSO}_{4} \cdot 7 \mathrm{H}_{2} \mathrm{O}\right)$ (E-Merck, India) were used for the synthesis of nanomaterials. Double distilled water was used for carrying out the experiments.

\section{Synthesis of cobalt doped nanomaterial}

Samples were synthesized by adopting a previously reported synthesis method.,29 Standard solutions of metal salts in deionized water were prepared, and these solutions were used in different stoichiometric amounts for precipitation. Hierarchical iron precursors with different morphologies were initially synthesized using a solution-based sol-gel method. Nanomaterials were synthesized in a three necked flask equipped with a condenser containing $0.1 \mathrm{mmol}$ of iron salt solution. Required amount of cobalt sulphate solution was added dropwise to the homogeneous mixture during synthesis. The solution was stirred for 15 minutes and $\mathrm{pH}$ was monitored. Subsequently, $0.1 \mathrm{mmol}$ of EG solution was added and stirred at a speed of $400 \mathrm{rpm}$ by maintaining temperature at $95 \pm 5{ }^{\circ} \mathrm{C}$ for a given time period. Subsequently, the precipitate was collected and cooled at room temperature. The final product was obtained by separating the solid from liquid by centrifugation. The precipitate was washed thoroughly with distilled water and dried at $60{ }^{\circ} \mathrm{C}$ for 24 hours in a oven. The sample C0 was synthesized following the previous method reported in our earlier manuscript. ${ }^{29}$

The amounts of various precursors EG : Iron : Cobalt were maintained at (50:45:5) $\mathrm{ml}$ for sample $\mathrm{C} 1$ and $(50: 35: 15) \mathrm{ml}$ for sample $\mathrm{C} 2$ in $100 \mathrm{ml}$ salt solution. The doping \% was calculated as $1 \%$ for $\mathrm{C} 1$ sample and $3.6 \%$ for C2 sample via AAS analysis.
Iron and cobalt analysis was carried out via AAS. X-ray diffraction patterns were obtained by an instrument named PAnalytical model X'Pert PRO PW-3040/60 with Mo-K $\alpha$ radiation $(\lambda=0.709)$. The Fourier transform infrared (FT-IR) spectroscopic analyses were carried out using Nicolet 6700 spectrophotometer. The absorption spectra and optical properties of nanomaterials were studied in Perkin-Elmer UV-Visible spectrophotometer. The Raman spectra were obtained using micro Raman spectrophotometer from Renishaw (Renishaw plc, Gloucesteshire, UK). The morphology and particle size of nanomaterials were studied using a FESEM (field emission scanning electron microscope) ZEISS Merlin microscope and TEM (transmission electron microscope) from FEI, TECNAI G2 20, equipped with a GATAN CCD camera. The chemical states of the samples were evaluated by XPS (X-ray Photoelectron Spectroscopy), using a Thermo-VG Scientific ESCALab 250 microprobe. Surface area and pore size of the synthesized materials were estimated by nitrogen adsorption-desorption measurements on Quantachrome 1750 with ASiQ-WiN and Autosorb-iQ devices surface area analyzer. Cyclic voltammograms (CV) were obtained through the three-electrode workstation from $\mathrm{CHI}$ Instruments 660C. Herein, saturated calomel electrode was used as the reference electrode and platinum (Pt) wire was used as the counter electrode. The impedance study was carried out using a computer-controlled BioLogic SP-200 analyser.

\section{Electrochemical measurements}

Electrochemical properties were studied using a three-electrode system having synthesized nanomaterial on glassy carbon as the working electrode, a platinum electrode and SCE in $1 \mathrm{M} \mathrm{KOH}$ as the reference electrode in -1 to $-0.6 \mathrm{~V}$ potential range. The synthesized materials were spread over a glassy carbon electrode with carbon black and PTFE (Poly Tetra Fluoro Ethylene) in $7: 2: 1$ ratio and 2 drops of $5 \%$ Nafion were added and dried. Galvanostatic charge-discharge study was performed using chrono-potentiometric method at various current densities. Electrochemical impedance spectroscopy (EIS) was investigated in the frequency range from $1 \mathrm{~Hz}$ to $1 \mathrm{MHz}$. All the above measurements were carried out in $1 \mathrm{M} \mathrm{KOH}$ electrolyte.

\section{Results and discussion}

XRD patterns of undoped and doped samples C0, C1 and C2, respectively, are shown in Fig. 1. The undoped pure iron sample was named as $\mathrm{C} 0$. The undoped sample $\mathrm{C} 0$ obtained as pure hematite phase was obtained where all the crystalline peaks matched with JCPDS - 01-084-0310. Moreover, both the doped samples $\mathrm{C} 1$ and $\mathrm{C} 2$ were obtained with crystalline peaks of goethite $(\alpha-\mathrm{FeOOH})$ with JCPDS file no. - 00-029-713 and cobalt ferrite $\left(\mathrm{CoFe}_{2} \mathrm{O}_{4}\right)$ with JCPDS file no. - 00-001-1121. From Fig. 1 it can be observed that all the crystalline peaks were well matched except the abolition of the peak at $2 \theta=18^{\circ}$. In case of sample $\mathrm{C} 1$ there were two peaks around $2 \theta=18^{\circ}$, but with the increase in doping percentage, the two peaks emerged as one peak for C2 sample. In general, it was observed that the $\alpha$-FeOOH phase was the major direct hydrolysis product., ${ }^{50-34}$ 


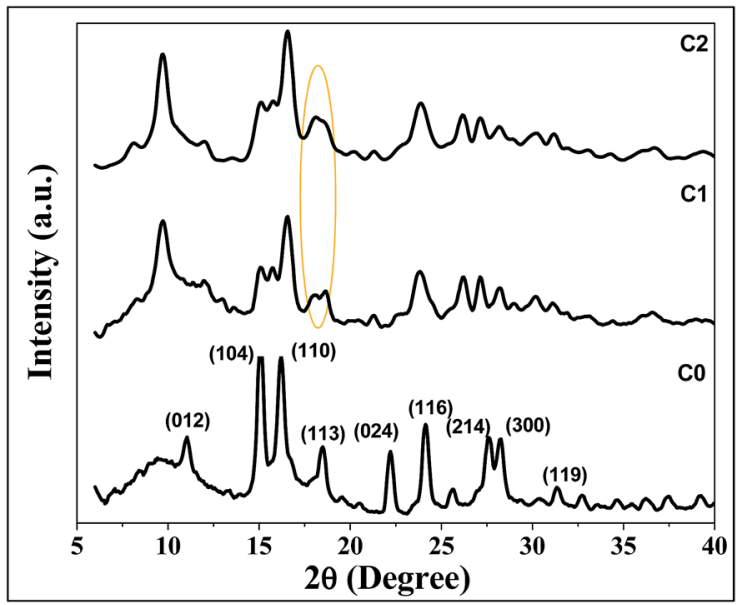

Fig. 1 XRD patterns of synthesized iron oxide in presence of cobalt in EG solvent mediated precipitation routes.

However, depending on the surface energetics, sizes and environment, different phases of $\mathrm{Fe}(\mathrm{III})$ oxides/oxyhydroxides/ hydroxides with addition of cobalt were formed in case of C1 and C2 samples. The C0 sample is the most stable $\alpha-\mathrm{Fe}_{2} \mathrm{O}_{3}$ phase but due to the addition of secondary metal ion cobalt, $\mathrm{C} 1$ and $\mathrm{C} 2$ evolved with $\alpha$-FeOOH phase with lower surface energy. Moreover, a change in the diffraction peak area, shifting of the peaks and their intensities are observed due to the effect of secondary metal ion.

It is observed that, even at higher concentration of metal ion, the formation other phases of iron oxides was not possible; only signature peaks of goethite and phase were observed in the presence of cobalt. Again, the probability of precipitation of pure phase of cobalt oxide or other associated compounds was not projected.

The doping of Co was also confirmed by the Raman study, as given in ESI Fig. S1. $\dagger$

\section{Nanostructure analysis of synthesized doped iron oxides samples}

Fig. 2 represents the structural properties and particle size of the synthesized samples obtained by FESEM and TEM studies. FESEM study gives a clear idea about the morphology and average particle size of the synthesized nanomaterials (Fig. S2†). Table S1† represents the average length and width of nanoparticles, which were manually calculated on 50 isolated particles. The average particle size is (in length and width) increased with an increase in cobalt concentration and depends on the precursor source (see Fig. S2 $\dagger$ ). The nitrate oxyanions may be incorporated or adsorbed during nucleation and growth of iron nanocrystals.

Literature study reveals that the crystal growth processes are dependent on the presence of external metal ions, molecules and ligands, which affects the morphology, average particle size, specific surface area, various physical properties, etc. ${ }^{35,36}$

The particles self-assembled and formed flowery particles at the highest concentration of cobalt. For this, the particle surface

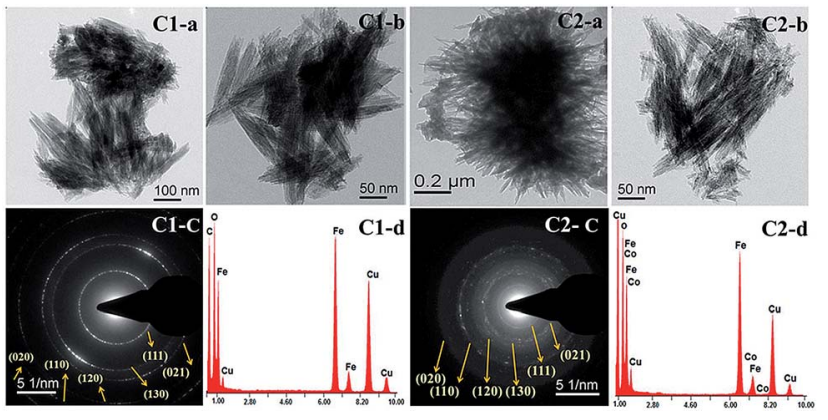

Fig. 2 C1-a \& C1-b represents the TEM images of C1 sample, C1- $C$ corresponding SAED pattern of C1 sample and C1-d EDAX data of C1 sample. C2-a \& C2-b represents the TEM images of C2 sample, C2-C corresponding SAED pattern of $C 2$ sample and C2-d EDAX analysis of C2 sample.

hinders the further growth of nanoparticles and facilitates them to assemble into flower like nanostructures under the cooperative assistance of the cobalt ion interaction, which lowers their energy. Further insights with respect to morphology have been provided with the help of TEM observations of the samples.

Based on better electrochemical properties of the samples (discussed in detail later), TEM study of selected samples was carried out, and the sample prepared at lowest concentration of metal ion was also incorporated for comparison.

Microscopic images with corresponding SAED (selected area electron diffraction) patterns and EDAX (Energy Dispersive X-ray spectroscopy) analysis of synthesized nano-materials are given in Fig. 2. A nanorod structure with an average length : width ratio of 16 with aggregation was seen for C1. These rods were of single domain and less developed at the ends. However, the growth of particle under highest concentration of cobalt in the present study terminated in welldeveloped (021) plane but these particles were not as long or as thin, which could suggest a disturbance in crystal growth due to incorporation of Co. Parallel alignments of rods along with twined crystals of goethite are also observed. At a higher concentration of cobalt, the flowery shape assembly of rods is visible. The obtained EDAX data from TEM analysis showed the presence of $\mathrm{Fe}, \mathrm{Co}$, and $\mathrm{O}$ along with $\mathrm{Cu}$ and $\mathrm{C}$ radiation originating from the precursor material and copper grid used for the detection, respectively. As shown in SAED patterns of both the samples, the crystallinity of the samples decreased as the \% cobalt increased in the matrix.

Several authors ${ }^{21,37,38}$ have reported that for synthesized goethite material, prisms elongated in the direction of $c$ axis, restricted by (110), (100), and (010) faces and surpassed mostly by (021) or (001) faces, are formed. In our case, the cobalt doped sample showed tips with triangular morphology with broken faces. The probable plane orientation and corresponding tips developed under different conditions are shown in schematic presentation in Fig. 3.

\section{Surface area analysis}

The BET surface area obtained through nitrogen adsorption/ desorption isotherms and $\mathrm{BJH}$ pore size distribution of the samples $\mathrm{C} 1$ and $\mathrm{C} 2$ are shown in Fig. 4. Both the samples showed 


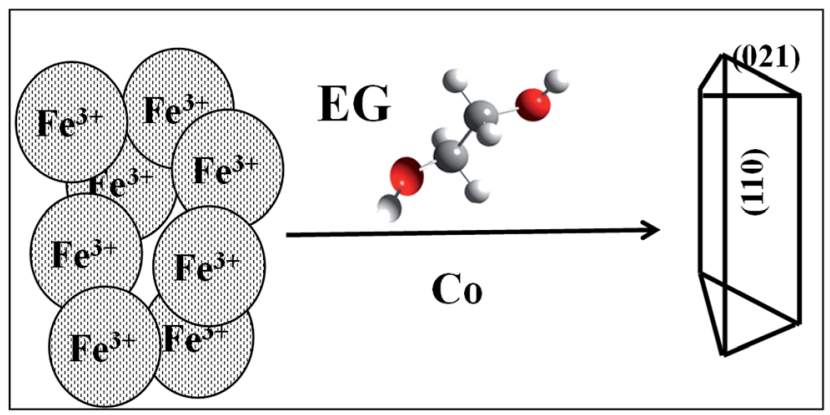

Fig. 3 The schematic representation of the shape of Co doped goethite nano-rods. Possible morphology along with shape of tips is drawn in the appropriate orientation as observed from TEM analysis as seen in Fig. 2.

typical type IV isotherm with H3-type hysteresis loop associated with slit-shaped pores containing mesopores. The relative flowerlike nano-architectures $\mathrm{C} 2$ sample has the hysteresis loop at a relative pressure $P / P_{0}$ of 0.45 to 1.0 and a multimodal pore diameter within 1 to $5 \mathrm{~nm}$. For the $\mathrm{C} 2$ sample, a smaller hysteresis loop of the isotherm was observed compared to C1, which has relatively low cobalt content. However, the observed $P / P_{0}$ value was $0.50-0.95$ for $\mathrm{C} 1$ sample. The data listed below (Table 1) demonstrate that the BET surface area $\left(180.22 \mathrm{~m}^{2} \mathrm{~g}^{-1}\right)$ and total pore volume of the $\mathrm{C} 1$ sample is slightly more than that of $\mathrm{C} 2$ sample $\left(\mathrm{SA}=159.74 \mathrm{~m}^{2} \mathrm{~g}^{-1}\right)$. The loss of BET surface area and pore volume may be due to the agglomeration of nanorods and porosity obtained due to the external surface of the materials.

The mesoporosity of nanomaterial helps more feasible movement of hydroxide ions with active charge storage sites for electrochemical reactions with higher current density. The capacitance may be enhanced with the specific surface area and effective pores. The increase in surface area initiates the redox active sites for metal oxides loading, which affects the increase in capacitance..$^{\mathbf{3 9 4 0}}$

\section{XPS analysis}

The XPS analysis was carried out for C2 sample. Fig. 5 showed that the binding energies for $\mathrm{C} 2$ sample of $\mathrm{Fe} 2 \mathrm{p}_{3 / 2}$ and $\mathrm{Fe} 2 \mathrm{p}_{1 / 2}$ are 711 and $724.7 \mathrm{eV}$, respectively, which are reliable with the

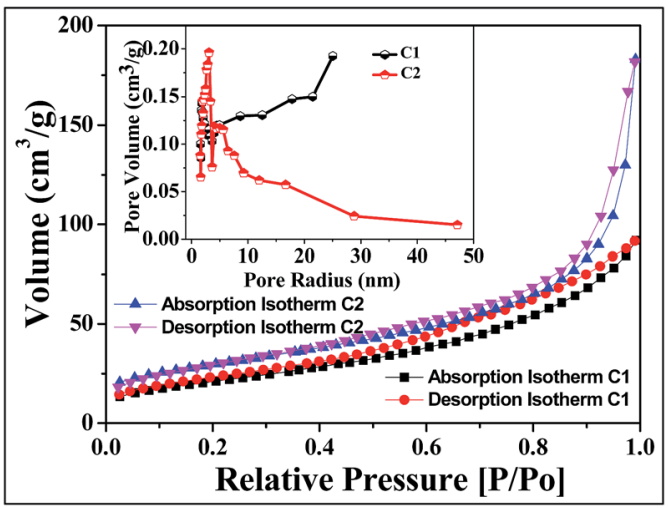

Fig. 4 Surface area and pore volume of EG mediated cobalt doped goethite.
Table 1 Surface area and pore volume of corresponding C1 \& C2 sample

\begin{tabular}{lll}
\hline Sample name & $\begin{array}{l}\text { Surface area } \\
\left(\mathrm{m}^{2} \mathrm{~g}^{-1}\right)\end{array}$ & $\begin{array}{l}\text { Pore volume } \\
\left(\mathrm{cm}^{3} \mathrm{~g}^{-1}\right)\end{array}$ \\
\hline $\mathrm{C} 1$ & 180.22 & 0.3905 \\
$\mathrm{C} 2$ & 159.74 & 0.2668
\end{tabular}

reported values for typical iron oxide. ${ }^{\mathbf{4 1 , 4 2}}$ Furthermore, satellite peak was observed at $719 \mathrm{eV}$. The binding energy value for $\mathrm{O} 1 \mathrm{~s}$ peak $(530.0 \mathrm{eV})$ and the energy difference between $\mathrm{O} 1 \mathrm{~s}$ and $\mathrm{Fe}$ $2 \mathrm{p}_{3 / 2}$ peaks and $\mathrm{BE}\left(\mathrm{O} 1 \mathrm{~s}-\mathrm{Fe} 2 \mathrm{p}_{3 / 2}\right)$, correspond with the expected values. The presence of surface hydroxyl groups was confirmed by the higher $\mathrm{BE}$ of $\mathrm{O} 1 \mathrm{~s}$ peak. In principle, these $\mathrm{OH}$ groups can be classified as three different types: free or isolated $\mathrm{OH}$ groups, $\mathrm{H}$ bonded $\mathrm{OH}$ groups and $\mathrm{OH}$ groups interacting with chemisorbed water molecules. The distribution of these groups is a function of the preparation conditions, such as temperature and sample dehydration degree. The Fe-O peak was observed at $530.0 \mathrm{eV}$, and the other two bands were due to chemically non-equivalent $\mathrm{OH}$ groups present on the surface of iron oxide. ${ }^{4-46}$ The binding energy of adsorbed oxygencontaining material and its amount varied due to the presence of cobalt. Peak shapes were differentiated by the rearrangement of weakly bound oxygen species. The Co $2 \mathrm{p}_{3 / 2}$ spectrum fitted to a single peak $(780.2 \mathrm{eV})$ with a characteristic satellite peak at $786.85 \mathrm{eV} .^{43}$ These observations confirmed that the product Co remains inside the goethite matrix.

\section{Optical properties of synthesized cobalt doped $\alpha$-FeOOH samples at various ratios}

As discussed earlier, rod shaped goethite particles were observed for all the synthesized samples. The UV-Vis spectra of some of the samples are shown in Fig. 6. Different absorption peaks at around $\sim 280 \mathrm{~nm}$ and $\sim 360 \mathrm{~nm}$ are observed in all the samples.

The UV-Vis spectra of goethite in general show three types of electronic transitions: (i) (Fe d-d) transitions, (ii) coupled Fe(III) ions interaction and (iii) $\mathrm{O}(2 \mathrm{p}) \rightarrow \mathrm{Fe}(3 \mathrm{~d})$ transition. The transitions with band positions $d$ include the charge transfer

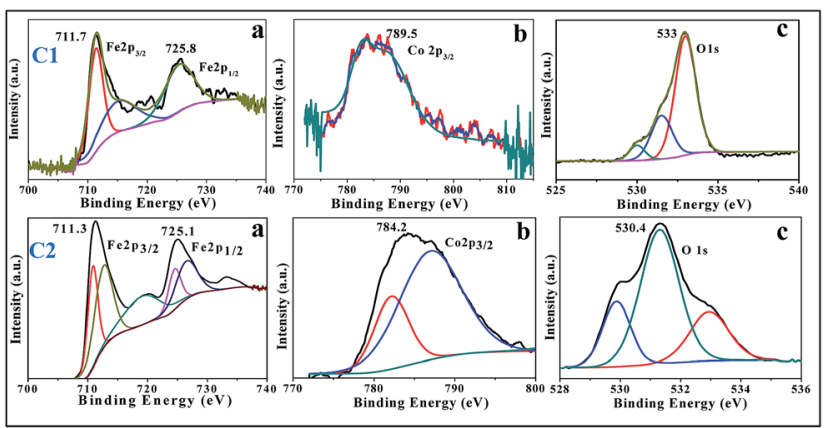

Fig. 5 XPS spectra of $\mathrm{C} 1$ and C2 sample, (a) Fe $2 p_{3 / 2}$ and $\mathrm{Fe} 2 \mathrm{p}_{1 / 2}$, (b) $\mathrm{Co} 2 \mathrm{p}_{3 / 2}$, (c) $\bigcirc 1 \mathrm{~s}$. 


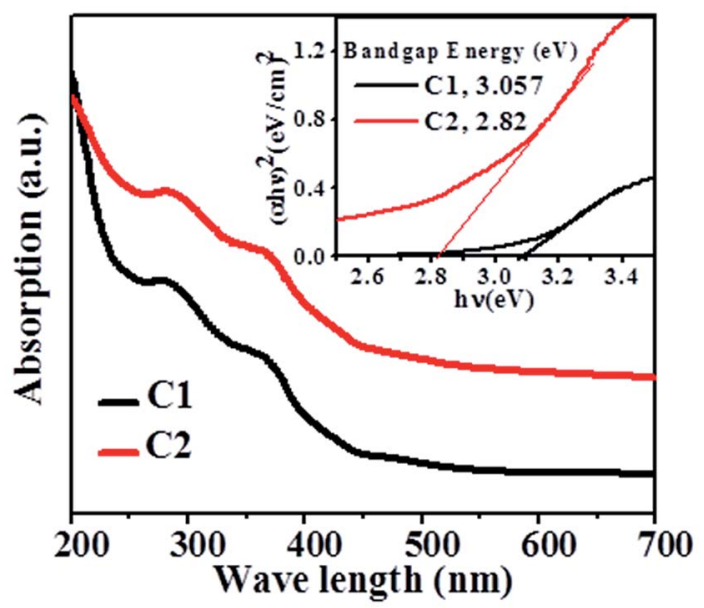

Fig. 6 UV spectra of Co doped goethite (C1 \& C2 sample) and band gap energy of corresponding samples (inset).

$6 \mathrm{~T}_{1 \mathrm{u}} \rightarrow 2 \mathrm{t}_{2 \mathrm{~g}}$ at $\sim 250 \mathrm{~nm}$ and the electron pair transition (EPT) $2\left(6 \mathrm{~A}_{1}\right) \rightarrow 2\left(4 \mathrm{~T}_{1}\right)(4 \mathrm{G})$ at $\sim 480 \mathrm{~nm}$ that primarily determine the absorption edge position (i.e., the optical band gap). ${ }^{47}$ As expected, the absorption peak positions were red-shifted because of increase in particle size with an increase in the $\mathrm{M}$ : Fe ratio in EG mediated samples. ${ }^{47}$

The band gap energy of all the photocatalysts was estimated from the plot of $(\alpha h \nu)^{n} v s . h \nu$ by extrapolating the straight line to the $X$ axis intercept. The band gap energy (as shown in Fig. 6) of $\mathrm{C} 1$ and $\mathrm{C} 2$ samples is found to be 3.057 and $2.82 \mathrm{eV}$ respectively.

\section{Electrochemical properties of as synthesized cobalt doped $\alpha$ - FeOOH samples}

Herein, observations of the electrochemical properties of the doped $\mathrm{FeOOH}$ samples were carried out by cyclic voltammetry (CV). The cyclic voltammetry (CV) curves were obtained with Pt as the counter-electrode and SCE as the reference electrode in $1 \mathrm{M} \mathrm{KOH}$ electrolyte.

The CV curves of doped FeOOH samples, as shown in Fig. 7, were obtained in a potential range from -1 to $-0.6 \mathrm{~V}$. It is clear that there were no redox peaks observed for both the samples $\mathrm{C} 1$ and $\mathrm{C} 2$. The shapes of the CV curves of are perfect doublelayer. The cation from the electrolyte could reversibly inset/ desert into/from the channels between the $\left[\mathrm{FeO}_{6}\right]$ octahedral subunits to store/release energy. ${ }^{48}$ The charge process compensated the $\mathrm{Fe}^{3+} / \mathrm{Fe}^{2+}$ redox reaction as shown in eqn (1) and (2) upon charging-discharging, and thus contributed to capacitive behavior of the cobalt doped $\alpha-\mathrm{FeOOH}$ nanorod electrode. $^{49}$

$$
\begin{gathered}
\mathrm{FeOOH}+\mathrm{H}_{2} \mathrm{O}+\mathrm{e}^{-} \rightarrow \mathrm{Fe}(\mathrm{OH})_{2}+\mathrm{OH}^{-} \\
\mathrm{Fe}^{3+}+\mathrm{e}^{-} \rightarrow \mathrm{Fe}^{2+}
\end{gathered}
$$

No redox peaks were observed in both the samples, which could be due to the presence of cobalt ion and a typical rectangular shape that appeared at different sweep rates, indicative

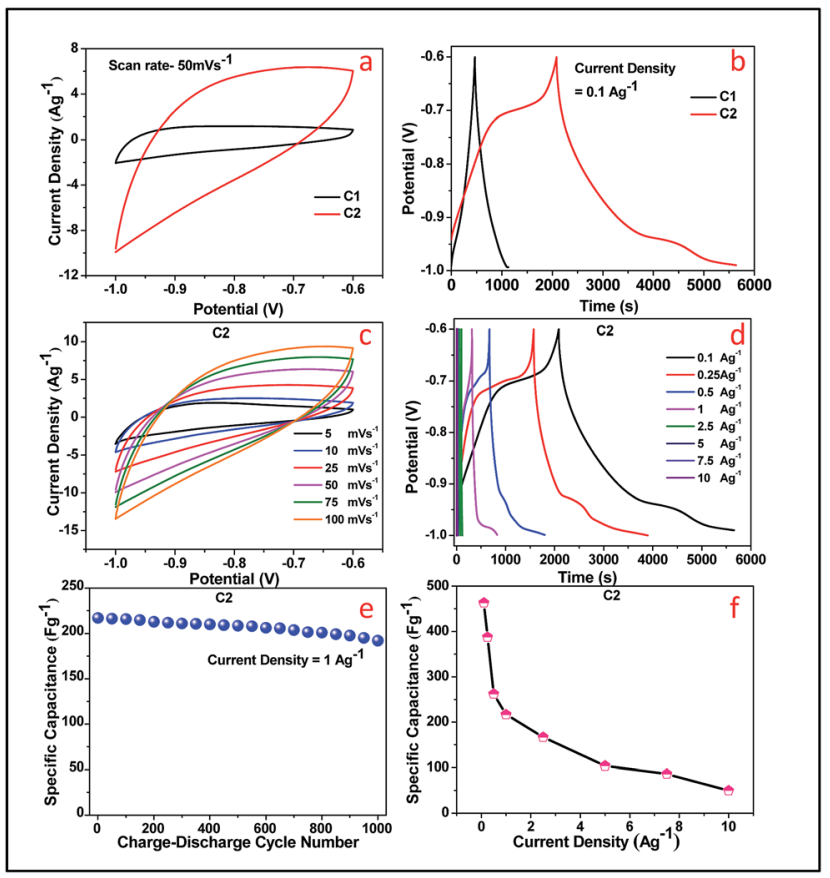

Fig. 7 Different electrochemical study Co doped goethite samples. (a) CV curves of C1 \& C2 electrodes at a scan rate of $50 \mathrm{mV} \mathrm{s}^{-1}$, (b) galvanostatic discharge curves of the $\mathrm{C} 1$ \& $\mathrm{C} 2$ electrodes at $0.1 \mathrm{~A} \mathrm{~g}^{-1}$, (c) $\mathrm{CV}$ curves and (d) galvanostatic discharge curves of cobalt doped $\mathrm{FeOOH}$-electrode at scan rates $\left(5-100 \mathrm{mV} \mathrm{s}^{-1}\right)$ and various current densities (10-0.1 $\mathrm{A} \mathrm{g}^{-1}$ ) respectively, (e) the retention in specific capacitance C2 electrode at $1 \mathrm{~A} \mathrm{~g}^{-1}$ current density, and (f) specific capacitance C2 sample at various current densities.

of good charge propagation at the electrode surface and corresponding to super capacitive behavior. However, increase in current density was observed for $\mathrm{C} 2$ sample. This may be due to the hindrance in kinetics of electron transportation in samples containing more amount of cobalt, which limited ion adsorption-desorption. However, in both the samples, there were no redox peaks but the cyclic voltammetry curves were obtained at a negative potential window with asymmetric behaviour, similar to the behaviour of an asymmetric capacitor. The asymmetry of the curves is most likely due to the combination of the double layer capacitance from secondary metal ions.

The specific capacitances of doped $\mathrm{FeOOH}$ were calculated using the following eqn (3):

$$
C_{\mathrm{s}}=I \Delta t / m \Delta V
$$

where " $I$ " is current in ampere, " $\Delta t$ " is discharging time in seconds, $m$ is the mass of the electro active materials and $\Delta V$ is the potential difference in volt. The CV curves of both the samples are given in Fig. 7a, whereas Fig. 7b represents the CD (charge-discharge) curves of $\mathrm{C} 2$ sample at current density $0.1 \mathrm{~A} \mathrm{~g}^{-1}$. The current density of $\mathrm{C} 2$ sample was increased possibly due to the presence of excess cobalt. Moreover, it shows tremendous electrochemical reversibility, negligible internal resistance and uniform working potentials of both the electrodes, even at high scan rates. ${ }^{6}$ 
Following eqn (3), the specific capacitance (SC) of C1 and C1 at a constant current density of $0.1 \mathrm{~A} \mathrm{~g}^{-1}$ was calculated as 160.67 $\mathrm{F} \mathrm{g}^{-1}$ and $463.18 \mathrm{~F} \mathrm{~g}^{-1}$, respectively.

A comparison Table $\mathrm{S} 2 \uparrow$ presents the specific capacitance of various $\mathrm{FeOOH}$ samples. The $\mathrm{SC}$ values were varied with percentage of doping. The outer and inner surfaces of the electrode were involved during charge/discharge process at slow scan rate, whereas only the outer surface of electrode was involved during fast scan rate, where ion transfer reaction occurred at a high current density. ${ }^{18}$ The Fig. 7c represents the cyclic voltammetry curves of $\mathrm{C} 2$ sample from scan rate $5 \mathrm{mV} \mathrm{s}^{-1}$ to $100 \mathrm{mV} \mathrm{s}^{-1}$. The current density increases with increasing scan rate from 5 to $200 \mathrm{mV} \mathrm{s}^{-1}$ and slow interaction between ions and electrode was possible. Fig. $7 d$ shows the increase in $\mathrm{SC}$ values with increase in current density from 0.1 to $10 \mathrm{~A} \mathrm{~g}^{-1}$ for $\mathrm{C} 2$ sample. The charge and discharge curves exhibit a good electrochemical reversibility without any deviation, which proves that it is the best super capacitive material. The nanorods demonstrate good charge-discharge cycle stability. The C1 electrode exhibits less specific capacitance value than $\mathrm{C} 2$, which reveals that Co ion doping has a positive effect of doping on $\mathrm{FeOOH}$ matrix. Co doped $\mathrm{FeOOH}$ electrodes were observed with enhanced specific capacitances and enhanced electrical conductivities by the incorporation of Co into the composite structure. This variation in SC value confirms that the doping of Co ions can improve the specific capacitance up to a certain concentration of dopant. Fig. 7e shows the retention in specific capacitance value up to $96.36 \%$ at $1 \mathrm{~A} \mathrm{~g}^{-1}$ current density for 1000 cycles, whereas Fig. $7 f$ presents the specific capacitance value of $\mathrm{C} 2$ sample at various current densities.

EIS measurements of doped FeOOH sample were carried out at a frequency range from $1 \mathrm{MHz}$ to $1 \mathrm{~Hz}$ in open circuit potential (OCP). Moreover, $1 \mathrm{M} \mathrm{KOH}$ aqueous solution was used as the electrolyte to study the resistance behaviour of supercapacitors, and the comparative Nyquist plots are explained in Fig. 8 for C2. The Nyquist plot obtained showed semicircular arc in low frequency region, whereas it displayed a straight line at a high frequency region. As shown in Fig. 8a for C2 sample, the semicircle can be attributed to the surface properties of the electrodes, including charge transfer resistance and doublelayer capacitance. $\mathrm{C} 2$ sample shows a semicircle but a vertical line (the angle degree with $x$-axis is more than $75^{\circ}$ ) appears, which proves that $\mathrm{C} 2$ has ideal capacitive behaviour. Furthermore, from Fig. $8 \mathrm{~b}$ it is observed that there is no change in

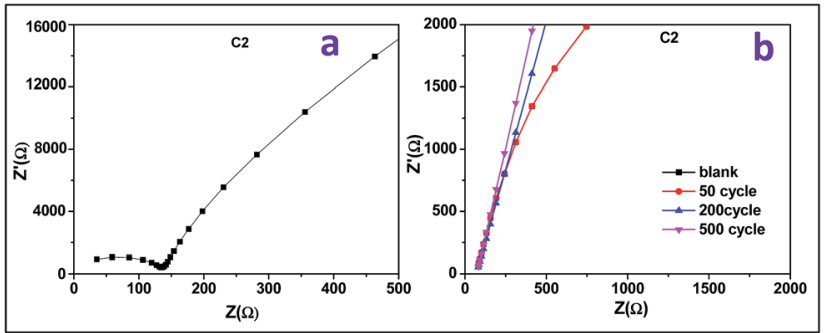

Fig. 8 EIS spectra of $\mathrm{Co}$ doped $\mathrm{FeOOH}$ in $\mathrm{KOH}$ electrolyte with frequency ranging from $1 \mathrm{~Hz}$ to $1 \mathrm{MHz}$. resistance value of the $\mathrm{C} 2$ sample even after 200 chargedischarge cycles.

\section{Conclusions}

Precipitation of iron oxides was carried out in the presence of cobalt in both EG solvent media. Samples were synthesized by varying the ratios of Co ions to Fe ions in solution during precipitation. XRD patterns of all the samples revealed that goethite was the only crystalline phase. However, depending on the nature of solvent and metal ions, development of specific planes, variation in their intensities and position are observed. TEM showed that the particle growth under highest concentration of cobalt in the present study terminated in welldeveloped (021) planes. The BET surface areas of samples were very high with porosity. The Co doped samples showed high specific capacitance values, which was speculated because one of the samples showed specific capacitance value of $463.18 \mathrm{~F} \mathrm{~g}^{-1}$ at $0.1 \mathrm{~A} \mathrm{~g}^{-1}$ current density with cycling stability of $96.36 \%$ over 1000 cycles.

\section{Conflicts of interest}

There are no conflicts of interest.

\section{Acknowledgements}

The authors are thankful to Prof. B. K. Mishra, Former Director, of the Institute of Minerals and Materials Technology, Bhubaneswar, for his kind permission to carry out the research work. The authors wish to thank Dr I. N. Bhattacharya, former Head of the Hydrometallurgy Department, CSIR-IMMT, Bhubaneswar. Rasmita Barik is thankful to DST Inspire Division (Govt. of India) for their financial support. The authors are thankful to the Prof. K. Mallick, Associate Prof., Department of Chemistry, from the University of Johannesburg for his kind help for the EIS measurement.

\section{Notes and references}

1 S. D. Perera, X. Ding, A. Bhargava, R. Hovden, A. Nelson, L. F. Kourkoutis and R. D. Robinson, Enhanced Supercapacitor Performance for Equal Co-Mn Stoichiometry in Colloidal $\mathrm{Co}_{3-x} \mathrm{Mn}_{x} \mathrm{O}_{4}$ Nanoparticles in Additive-Free Electrodes, Chem. Mater., 2015, 27, 7861-7873.

2 S. Li, J. Wen, T. Chen, L. Xiong, J. Wang and G. Fang, In situ synthesis of $3 \mathrm{D} \quad \mathrm{CoS}$ nanoflake/ $\mathrm{Ni}(\mathrm{OH})_{2}$ nanosheet nanocomposite structure as a candidate supercapacitor electrode, Nanotechnology, 2016, 27, 145401-145409.

$3 \mathrm{~J}$. Hou, C. Cao, F. Idrees and X. Ma, Hierarchical Porous Nitrogen-Doped Carbon Nanosheets Derived from Silk for Ultrahigh-Capacity Battery Anodes and Supercapacitors, ACS Nano, 2015, 9, 2556-2564.

4 R. Barik and M. Mohapatra, Solvent mediated surface engineering of $\alpha-\mathrm{Fe}_{2} \mathrm{O}_{3}$ nanomaterials: facet sensitive energy storage materials, CrystEngComm, 2015, 17, 92039215 . 
5 R. Barik, B. K. Jena, A. Dash and M. Mohapatra, In situ synthesis of flowery-shaped $\alpha$-FeOOH$/ \mathrm{Fe}_{2} \mathrm{O}_{3}$ nanoparticles and their phase dependent supercapacitive behaviour, $R S C$ Adv., 2014, 4, 18827-18834.

6 Y.-G. Lin, Y.-K. Hsu, Y.-C. Lin and Y.-C. Chen, Hierarchical $\mathrm{Fe}_{2} \mathrm{O}_{3}$ nanotube/nickel foam electrodes for electrochemical energy storage, Electrochim. Acta, 2016, 20, 287-294.

7 J. Xu, L. Gao, J. Cao, W. Wang and Z. Chen, Preparation and electrochemical capacitance of cobalt oxide $\left(\mathrm{Co}_{3} \mathrm{O}_{4}\right)$ nanotubes as supercapacitor material, Electrochim. Acta, 2010, 56, 732-736.

8 J. Wu, C. Ouyang, S. Dou and S. Wang, Hybrid NiS/CoO mesoporous nanosheet arrays on $\mathrm{Ni}$ foam for high-rate supercapacitors, Nanotechnology, 2015, 26, 325-401.

9 G. D. Nie, X. F. Lu, J. Y. Lei, Z. Q. Jiang and C. Wang, Electrospun $\mathrm{V}_{2} \mathrm{O}_{5}$-doped a- $\mathrm{Fe}_{2} \mathrm{O}_{3}$ composite nanotubes with tunable ferromagnetism for high performance supercapacitor electrodes, J. Mater. Chem. A, 2014, 2, 15495-15501.

10 Y. Liu, Y. Jiao, Z. Zhang, F. Qu, A. Umar and X. Wu, Hierarchical $\mathrm{SnO}_{2}$ nanostructures made of intermingled ultrathin nanosheets for environmental remediation, smart gas sensor, and supercapacitor applications, ACS Appl. Mater. Interfaces, 2014, 6, 2174-2184.

11 K. J. Huang, J. Z. Zhang and Y. Fan, One-step solvothermal synthesis of different morphologies CuS nanosheets compared as supercapacitor electrode materials, J. Alloys Compd., 2015, 625, 158-163.

12 S. M Minakshi, A. Biswal, D. Mitchell, R. Jones and C. Fernandez, Correlation among physical and electrochemical behaviour of nanostructured electrolytic manganese dioxide from leach liquor and synthetic for aqueous asymmetric capacitor, Phys. Chem. Chem. Phys., 2016, 18, 4711-4720.

13 Y. Lin, X. Wang, G. Qian and J. J. Watkins, Additive-Driven Self-Assembly of Well-Ordered Mesoporous Carbon/Iron Oxide Nanoparticle Composites for Supercapacitors, Chem. Mater., 2014, 26, 2128-2137.

14 P. S. Khiew, M. Y. Ho, T. K. Tan, W. S. Chiu, R. Shamsudin, M. A. Abd-Hamid and C. H. Chia, Synthesis and Electrochemical Characterization of Iron Oxide/Activated Carbon Composite Electrode for Symmetrical Supercapacitor, Int. J. Chem., Mol., Nu., Mat. and Metal. Eng., 2013, 7, 8.

15 Q. Xia, M. Xu, H. Xia and J. Xie, Nanostructured Iron Oxide/ Hydroxide-Based Electrode Materials for Supercapacitors, ChemNanoMat, 2016, 2, 588-600.

16 C. Guan, J. Liu, Y. Wang, L. Mao, Z. Fan, Z. Shen, H. Zhang and J. Wang, Iron oxide-decorated carbon for supercapacitor anodes with ultrahigh energy density and outstanding cycling stability, ACS Nano, 2015, 26, 5198-5207.

17 Z. Ma, X. Huang, S. Dou, J. Wu and S. Wang, One-Pot Synthesis of $\mathrm{Fe}_{2} \mathrm{O}_{3}$ Nanoparticles on Nitrogen-Doped Graphene as Advanced Supercapacitor Electrode Materials, J. Phys. Chem. C, 2014, 118, 17231-17239.

$18 \mathrm{~S}$. Ghasemi and F. Ahmadi, Effect of surfactant on the electrochemical performance of graphene/iron oxide electrode for supercapacitor, J. Power Sources, 2015, 289, 129-137.

19 G. S. Gund, D. P. Dubal, N. R. Chodankar, J. Y. Cho, P. Gomez-Romero, C. Park and C. D. Lokhande, Low-cost flexible supercapacitors with high-energy density based on nanostructured $\mathrm{MnO}_{2}$ and $\mathrm{Fe}_{2} \mathrm{O}_{3}$ thin films directly fabricated onto stainless steel, Sci. Rep., 2015, 5, 12454.

20 Q. Qu, S. Yang and X. Feng, 2D Sandwich-like Sheets of Iron Oxide Grown on Graphene as High Energy Anode Material for Supercapacitors, Adv. Mater., 2011, 23, 5574-5580.

21 G. J. Kroes, A. Gross, E. J. Baerends, M. Scheffler and D. A. Mc Cormack, Quantum theory of dissociative chemisorption on metal surfaces, Acc. Chem. Res., 2002, 35, 193-200.

22 P. V. Kamat, K. Tvrdy, D. R. Baker and J. G. Radich, Beyond photovoltaics: semiconductor nanoarchitectures for liquidjunction solar cells, Chem. Rev., 2010, 110, 6664-6688.

23 Y. Jun, D. Yu, M. C. George and P. V. Braun, Holographically Defined Nanoparticle Placement in 3D Colloidal Crystals, $J$. Am. Chem. Soc., 2010, 132, 9958-9959.

24 Y. Zhao, S. Chen, B. Sun, D. Su, X. Huang, H. Liu, Y. Yan, K. Sun and G. Wang, Graphene- $\mathrm{Co}_{3} \mathrm{O}_{4}$ nanocomposite as electrocatalyst with high performance for oxygen evolution reaction, Sci. Rep., 2015, 5, 7629-7635.

$25 \mathrm{~K}$. Chen and D. Xue, Room-Temperature Chemical Transformation Route to $\mathrm{CuO}$ Nanowires toward HighPerformance Electrode Materials, J. Phys. Chem. C, 2013, 117, 22576-22583.

26 Y. Ling, G. Wang, D. A. Wheeler, J. Z. Zhang and Y. Li, SnDoped Hematite Nanostructures for Photoelectrochemical Water Splitting, Nano Lett., 2011, 11, 2119-2125.

27 M. Zhang, K. Chen, X. Chen, X. Peng, X. Sun and D. Xue, Crystallization of $\mathrm{FeOOH}$ via iron salts: an anionchemoaffinity controlled hydrolysis toward high performance inorganic pseudocapacitor materials, CrystEngComm, 2015, 17, 1917-1922.

28 S. Shivakumara, T. R. Penki and N. Munichandraiah, High specific surface area $\alpha-\mathrm{Fe}_{2} \mathrm{O}_{3}$ nanostructures as high performance electrode material for supercapacitors, Mater. Lett., 2014, 131, 100-103.

29 R. Barik, S. K. Tripathy and M. Mohapatra, Hierarchical pseudo-cubic hematite nanoparticle as formaldehyde sensor, J. Mater. Sci., 2014, 49, 5345-5354.

30 R. Barik, B. Pandey, S. Anand and M. Mohapatra, Facile single step synthesis of flowery shape pure/lithium doped 3D iron oxides, J. Mater. Chem. A, 2014, 2, 12380-12389.

31 S. N. Beznosov, P. S. Veluri, M. G. Pyatibratov, A. Chatterjee, D. R. MacFarlane, O. V. Fedorov and S. Mitra, Flagellar filament bio-templated inorganic oxide materials - towards an efficient lithium battery anode, Sci. Rep., 2015, 5, 77367742.

32 L. Zhang, H. B. Wu and X. W. Lou, Iron-Oxide-Based Advanced Anode Materials for Lithium Ion Batteries, Adv. Energy Mater., 2014, 4, 1300958-1300967.

33 K. Rout, M. Mohapatra, S. Layek, A. Dash, H. C. Verma and S. Anand, The influence of precursors on phase evolution of nano iron oxides/oxyhydroxides: optical and magnetic properties, New J. Chem., 2014, 38, 3492-3506. 
34 R. Suresh, K. Giribabu, R. Manigandan, A. Vijayaraj, R. Prabu, A. Stephen and V. Narayanan, $\alpha-\mathrm{Fe}_{2} \mathrm{O}_{3}$ nanoflowers: synthesis, characterization, electrochemical sensing and photocatalytic property, J. Iran. Chem. Soc., 2014, 11, 645-652.

35 G. A. Waychunas, C. S. Kim and J. F. Banfield, Nanoparticulate iron oxide minerals in soils and sediments: unique properties and contaminant scavenging mechanisms, J. Nanopart. Res., 2005, 7, 409-433.

$36 \mathrm{H}$. Guo and A. S. Barnard, Thermodynamic modelling of nanomorphologies of hematite and goethite, J. Mater. Chem., 2011, 21, 11566-11577.

37 X. Mao, H. C. Yang, X. M. Zhou, C. X. Wang, Y. S. Wang, Y. L. Yang, C. Wang and G. Liu, Straight and branched goethite topology by oriented attachment at high $\mathrm{pH}$, Cryst. Growth Des., 2010, 10, 504-509.

38 H. C. Zeng, Oriented Attachment: A Versatile Approach for Construction of Nanomaterials, J. Nanotechnol., 2007, 4, 329-346.

39 L. Vayssieres, K. Keis, A. Hagfeldt and S. E. Lindquist, Threedimensional array of highly oriented crystalline $\mathrm{ZnO}$ microtubes, Chem. Mater., 2001, 13, 4395-4398.

40 W. Sakamoto, Y. Masuda and T. J. Yogo, Fabrication and properties of perovskite $\mathrm{Pb}(\mathrm{Yb}, \mathrm{Nb}) \mathrm{O}_{3}-\mathrm{PbTiO}_{3}$ thin films through a sol-gel process, J. Alloys Compd., 2006, 408, 543546.

41 H. Liu, J. Xie and K. Wang, Synthesis and characterization of nano-LiFePO 4 /carbon composite cathodes from 2methoxyethanol-water system, J. Alloys Compd., 2008, 459, 521-525.

42 H. Yang, S. Han, L. Wang, I. J. Kim and Y. Son, Preparation and characterization of indium-doped tin dioxide nanocrystalline powders, Mater. Chem. Phys., 1998, 56, 153-156.

43 A. S. Adekunle, B. O. Agbool, K. I. Ozoemen, E. E. Ebenso, J. A. O. Oyekunle, O. S. Oluwatobi and J. N. Lekitim, Comparative Supercapacitive Properties of Asymmetry Two Electrode Coin Type Supercapacitor Cells made from MWCNTS/Cobalt Oxide and MWCNTs/Iron Oxide Nanocomposite, Int. J. Electrochem. Sci., 2015, 10, 3414-3430.

44 G. Tong, J. Guan and Q. Zhang, Goethite hierarchical nanostructures: Glucose-assisted synthesis, chemical conversion into hematite with excellent photocatalytic properties, Mater. Chem. Phys., 2011, 127, 371-378.

45 Z. C. Li, M. Y. Guan, Z. S. Lou and T. M. Shang, Facile hydrothermal synthesis and electrochemical properties of hollow urchin-like $\alpha$-FeOOH, Micro Nano Lett., 2012, 7, 3336.

46 Q. Shou, J. Cheng, L. Zhang, B. J. Nelson and X. Zhang, Synthesis and characterization of a nanocomposite of goethite nanorods and reduced graphene oxide for electrochemical capacitors, J. Solid State Chem., 2012, 185, 191-197.

47 Y. Zhang, H. Feng, X. B. Wu, L. Z. Wang, A. Q. Zhang, T. C. Xia, H. Dong, X. Li and L. Zhang, Progress of electrochemical capacitor electrode materials: A review, Int. J. Hydrogen Energy, 2009, 34, 4889-4899.

48 J. G. Wang, Y. Yang, Z. H. Huang and F. J. Kang, Interfacial synthesis of mesoporous $\mathrm{MnO}_{2}$ /polyaniline hollow spheres and their application in electrochemical, J. Power Sources, 2012, 204, 236-243.

49 N. Nagarajan and I. Zhitomirsky, Cathodic electrosynthesis of iron oxide films for electrochemical supercapacitors, $J$. Appl. Electrochem., 2006, 36, 1399-1405. 